\title{
Do risk premia protect against banking crises?
}

\section{Journal Article}

\section{Author(s):}

Gersbach, Hans; Wenzelburger, Jan

Publication date:

2008

Permanent link:

https://doi.org/10.3929/ethz-b-000003663

\section{Rights / license:}

In Copyright - Non-Commercial Use Permitted

\section{Originally published in:}

Macroeconomic Dynamics 12, https://doi.org/10.1017/S1365100508070259 


\title{
DO RISK PREMIA PROTECT AGAINST BANKING CRISES?
}

\author{
Hans Gersbach \\ ETH Zurich \\ and \\ CEPR
}

\section{JaN WenZeLburGer \\ Keele University}

\begin{abstract}
This paper examines the question to what extent premia for macroeconomic risks in banking are sufficient to avoid banking crises. We investigate a competitive banking system embedded in an overlapping-generations model subject to repeated macroeconomic shocks. We show that even if banks fully incorporate macroeconomic risks into their pricing of loans, a banking system may enter bankruptcy with probability one. A major cause for this default is that risk premia of a competitive banking system may become too small if the capital base is low.
\end{abstract}

Keywords: Financial Intermediation, Macroeconomic Risks, Banking Crises, Risk Premia, Banking Regulation

\section{INTRODUCTION}

Severe banking crises are ubiquitous in our times. A banking crisis occurs when a large number of banks fails to meet regulatory capital requirements, is illiquid, or is insolvent. Most banking crises can be attributed to negative macroeconomic shocks, including their amplification mechanisms. Many investigations provide empirical evidence that the crises in Latin America of the 1980s and early 1990s, those in East Asia later that decade, and the more prolonged stagnation in Japan, for example, were to a large extent caused by negative macroeconomic events; see, e.g., Borio (2003). The devastating effects of banking crises on economies, including budgetary consequences of possible government bailouts, have brought the problem of optimal policy design to the top of the international policy agenda. A fundamental question for any policy design in banking and in crisis management is to what extent a banking system is capable of protecting itself against macroeconomic risks and thus against financial instabilities.

\footnotetext{
We would like to thank Alex Cukierman, Volker Böhm, Leo Kaas, Jean-Charles Rochet, Gilles Saint-Paul, Rune Stenbacka, Eva Terberger-Stoy, Jean Tirole, participants of seminars in Bielefeld, Frankfurt, Helsinki, and Toulouse, and participants at the Conference of Dynamic Macroeconomics in Copenhagen 2004 for valuable comments and suggestions. Address correspondence to: Hans Gersbach, Center of Economic Research, Eidgenössische Technische Hochschule Zurich, Zürichbergstrasse 18, 8092 Zurich, Switzerland; e-mail: hgersbach@ethz.ch.
} 
Based on a dynamic macroeconomic model with overlapping generations and financial intermediation, the present paper addresses the issue of to what extent premia for macroeconomic risks protect against banking crises. Free exit and free entry in a competitive banking sector determine the price for macroeconomic risks, which is reflected by the risk premium of loans. Deposits are implicitly insured. The model complements earlier business cycle models with financial intermediation such as Boyd and Prescott (1986), Williamson (1987), Uhlig (1995), and Schreft and Smith (1997), which do not focus on banking crises.

Two insights into the vulnerability of a competitive banking system to macroeconomic shocks will be provided. First, risk premia charged by banks will depend on their capital base. It is intuitively clear that risk premia are small when the capital base of the banking system is small. Indeed, at the limit when bank capital is zero, the risk premium vanishes, because otherwise the return on bank capital would become arbitrarily large. As a consequence, a banking system with low capital is more vulnerable to a further decline of capital than a system with high capital. Second, if bank capital is below a critical level, the banking system will default with certainty in finite time. The reason for this is a vicious circle. Repeated negative macroeconomic shocks spill over to the balance sheets of banks and lower their bank capital. As risk premia decrease, the likelihood of further declines of capital increases. Over time the banking system will default.

The focus of this paper is on economic results. Detailed justifications of the setup and the nature of market failures and a discussion of related literature are found in Gersbach and Wenzelburger $(2004,2007)$. This paper is organized as follows. In the next section we introduce the model. Existence and uniqueness of temporary equilibria with financial intermediation are discussed in Section 3. A stochastic difference equation governing the evolution of bank capital is set up in Section 4. In Section 5 we analyze the relationship between default probabilities and risk premia, and in Section 6 the default risks of the banking system. Section 7 concludes.

\section{MODEL}

\subsection{Entrepreneurs and Depositors}

Consider an overlapping-generations (OLG) model with financial intermediation in which one physical good that can be used for consumption or investment. Time is infinite in the forward direction and divided into discrete periods indexed by $t$. Each generation consists of a continuum of agents with two-period lives, indexed by $[0,1]$. Each agent of each generation receives an endowment $e$ of goods when young and none when old. Generations are divided into two classes. One fraction of agents, indexed by $[0, \eta]$, are potential entrepreneurs; the other fraction are consumers and are indexed by $(\eta, 1]$. Potential entrepreneurs and consumers differ in that only the former have access to investment technologies. 
Consumers are endowed with intertemporal preferences over consumption in the two periods of their lives. Let $u\left(c_{t}^{1}, c_{t}^{2}\right)$ be a standard intertemporal utility function of a consumer, with $c_{t}^{1}, c_{t}^{2}$ denoting youthful and old-age consumption of a consumer born in period $t$, respectively. Given the endowment $e$ when young and a deposit interest rate $r^{\mathrm{d}}$, each young household saves the amount $s\left(r^{\mathrm{d}}\right)$. Aggregate savings of all households are then denoted by $S\left(r^{\mathrm{d}}\right)$ and given by $S\left(r^{\mathrm{d}}\right)=(1-\eta) s\left(r^{\mathrm{d}}\right)$.

Potential entrepreneurs are assumed to be risk-neutral and consume only when old. Each entrepreneur decides whether to save his endowment or to invest into a production project that converts period- $t$ goods into period- $(t+1)$ goods. The funds required for an investment project are fixed to $e+I$ so that an entrepreneur must borrow $I$ additional units of the good from banks in order to undertake the investment project. Entrepreneurs are heterogeneous, as the quality of their investment projects depends on their index $i$. The quality parameter of entrepreneur $i$ is assumed to be a private signal given by $1+i$. If an entrepreneur of type $i$ obtains additional resources $I$ and decides to invest, his output $y$ in the next period is determined by

$$
y=q(1+i) f(e+I),
$$

where $f$ denotes a standard atemporal neoclassical production function. The parameter $q \in[q, \bar{q}]$ describes the macroeconomic shock affecting the productivity of the entrepreneurs and thus causing fluctuations of aggregate output.

All entrepreneurs are price takers and operate under limited liability. They may apply for a loan contract at a bank that offers intermediation services. Given a loan interest rate $r^{\mathrm{c}}$, the expected profit of an investing entrepreneur $i$ is

$$
\Pi\left(i, r^{\mathrm{c}}\right):=\int_{\underline{q}}^{\bar{q}} \max \left\{(1+i) q f(e+I)-I\left(1+r^{\mathrm{c}}\right), 0\right\} \mu(d q),
$$

where $\mu$ denotes the probability distribution of the shocks. Note that $\Pi\left(i, r^{\mathrm{c}}\right)$ is increasing in quality levels $i$ and decreasing in loan rates $r^{\mathrm{c}}$. Entrepreneurs face a binary decision problem, such that a risk-neutral entrepreneur with quality parameter $i \in[0, \eta]$ will invest, if

$$
\Pi\left(i, r^{\mathrm{c}}\right) \geq e\left(1+r^{\mathrm{d}}\right) .
$$

\subsection{Banking Sector}

There is a competitive banking system with limited liability that consists of $n$ ( $n>$ 1) identical banks, indexed by $j=1, \ldots, n$, which are owned by entrepreneurs. Banks finance entrepreneurs and maximize profits or bank capital accruing to current shareholders. Transfer of ownership of banks to the next generation occurs through bequests. Because the banking industry is perfectly competitive and the number of banks is assumed to be large, banks take deposit and loan rates as 
given. However, banks freely decide whether or not to offer their intermediation services. ${ }^{1}$

Each bank $j$ can sign deposit contracts $D\left(r^{\mathrm{d}}\right)$, where $1+r^{\mathrm{d}}$ is the repayment offered for 1 unit of resources. Loan contracts of bank $j$ are denoted by $C\left(r^{\mathrm{c}}\right)$, while $1+r^{\mathrm{c}}$ is the repayment required from entrepreneurs for 1 unit of funds. All deposit and loan contracts last for one period. Banks act as delegated monitors, as depositors can observe neither the quality of investment projects nor whether entrepreneurs invest or consume their funds. They are assumed to be able to secure both the investment of an entrepreneur and the liquidation value in case of default. By (1), banks do not have to fear low-quality entrepreneurs applying for loans, as they are always better off with saving endowments.

The time line of actions in the economy within a typical period $t$ is as follows:

1. Old entrepreneurs pay back with limited liability. Banks pay back old depositors.

2. Given $r^{\mathrm{d}}$ and $r^{\mathrm{c}}$, banks decide whether to exit and to invest their capital somewhere else. If they stay in business, they offer their intermediation services.

3. Consumers and entrepreneurs decide which contracts to accept. Resources are exchanged.

4. Young entrepreneurs produce, subject to a macroeconomic shock.

We assume that deposit rates are guaranteed for all possible macroeconomic shocks. This assumption is adopted for two reasons. First, deposits are implicitly insured when the next generation has enough bailout incentives. Second, without deposit insurance, the willingness of consumers to save may decline when the banking system faces a positive default probability. This, in turn, could accelerate an actual default. In this sense, the assumption that deposits are insured by the next generation provides a lower bound on default probabilities of a banking system.

To simplify the exposition, we set the costs of intermediation to zero and make the following assumptions regarding the behavior of banks. Banks operate under limited liability. Depositors randomly choose a bank that offers its intermediation services in order to save. Similarly, entrepreneurs applying for a loan contract choose banks randomly. Throughout the paper, we assume that uncertainty is canceled out when depositors and entrepreneurs randomly choose banks. That is, each active bank obtains the same amount of deposits and loans. Loans are constrained by the amount of deposits obtained. If entrepreneurs applying for loans are rejected, they will randomly choose a bank and save.

Finally, banks can exit completely, but cannot partially reduce their equity while offering intermediation services. The assumption can be justified in several ways. First, it might be derived as an equilibrium phenomenon when banks are allowed to reduce their equity and deposits are not insured under all circumstances. For instance, consumers, upon observing the levels of equity, may decide to deposit their resources only at banks that have the highest level of equity, because those banks have the lowest default probability. Second, banks that offer their services are required by regulation to hold a certain amount of equity. Basel I and in the future Basel II are regulatory frameworks that stipulate such capital requirements for banks. 


\section{TEMPORARY EQUILIBRIA}

To derive an intermediation equilibrium, we assume that savings are never sufficient to fund all entrepreneurs, so that

$$
S\left(r^{\mathrm{d}}\right)=(1-\eta) s\left(r^{\mathrm{d}}\right)<\eta I \text { for all } r^{\mathrm{d}} \geq 0 .
$$

Otherwise all entrepreneurs would receive funds independent of their quality. Let $d$ denote the current capital base of the banking system. An individual bank has an equity level of $d_{j}=\frac{d}{n}$. As all banks are assumed to be identical, we will formulate the equilibrium conditions for the whole banking system and hence focus directly on the evolution of the aggregate bank capital $d$.

There are two boundary values for $d$. Let $S_{\max }:=\max \left\{S\left(r^{\mathrm{d}}\right): r^{\mathrm{d}} \geq 0\right\}$ denote maximal aggregate savings and set $\bar{d}:=\eta I-S_{\max }>0$ for an upper bound for the capital bases. If $d>\bar{d}$, we assume that banks pay excess capital to bank owners. On the other hand, if $d \leq 0$, then the capital base of the banking system has vanished, causing a default of the system. Thus an intermediation problem arises only when $d \in(0, \bar{d}]$. For each $d \in(0, \bar{d}]$ and each $r^{\mathrm{d}} \geq 0$, there exists a unique critical entrepreneur $i_{\mathrm{G}} \in[0, \eta]$, given by

$$
i_{\mathrm{G}}=i_{\mathrm{G}}\left(d, r^{\mathrm{d}}\right):=\frac{\eta I-S\left(r^{\mathrm{d}}\right)-d}{e+I},
$$

such that aggregate demand for loans is balanced by loan supply; that is,

$$
\left[\eta-i_{\mathrm{G}}\left(d, r^{\mathrm{d}}\right)\right] I=S\left(r^{\mathrm{d}}\right)+e i_{\mathrm{G}}\left(d, r^{\mathrm{d}}\right)+d, \quad d \in(0, \bar{d}] .
$$

Let $d \in(0, \bar{d}]$ be the current level of bank capital at the beginning of an arbitrary period. Suppose banks raise funds $S\left(r^{\mathrm{d}}\right)+e i_{\mathrm{G}}\left(d, r^{\mathrm{d}}\right)$ that have to be paid back with interest at the end of the subsequent period. Suppose that banks lend $\left[\eta-i_{\mathrm{G}}\right] I$ to firms. Then they will receive payments $P=P\left(i_{\mathrm{G}}, q, r^{\mathrm{c}}\right)$ at the end of the period, given by

$$
P\left(i_{\mathrm{G}}, q, r^{\mathrm{c}}\right)=\int_{i_{\mathrm{G}}}^{\eta} \min \left\{(1+i) q f(e+I), I\left(1+r^{\mathrm{c}}\right)\right\} d i,
$$

where $i_{\mathrm{G}}=i_{\mathrm{G}}\left(d, r^{\mathrm{d}}\right)$. Given a pair of interest rates $r^{\mathrm{d}}, r^{\mathrm{c}}$, the capital function of the banking system is given by a function $G\left(\cdot, q, r^{\mathrm{d}}, r^{\mathrm{c}}\right):(0, \bar{d}] \rightarrow \mathbf{R}$, defined by

$$
G\left(d, q, r^{\mathrm{d}}, r^{\mathrm{c}}\right)=P\left(i_{\mathrm{G}}\left(d, r^{\mathrm{d}}\right), q, r^{\mathrm{c}}\right)-\left[S\left(r^{\mathrm{d}}\right)+e i_{\mathrm{G}}\left(d, r^{\mathrm{d}}\right)\right]\left(1+r^{\mathrm{d}}\right),
$$

such that for each shock $q$ and each $r^{\mathrm{c}}, r^{\mathrm{d}} \geq 0, G\left(d, q, r^{\mathrm{d}}, r^{\mathrm{c}}\right)$ is the capital base of the banking system at the end of the period. The expected capital of banks which operate under limited liability is then $\mathbf{E}\left[\max \left\{G\left(d, q, r^{\mathrm{d}}, r^{\mathrm{c}}\right), 0\right\}\right]$. Formally, a temporary equilibrium with financial intermediation is defined as follows.

DEFINITION 1. Let $d \in(0, \bar{d}]$ denote the current level of bank capital. A temporary equilibrium with financial intermediation (TEFI) is a pair of interest 
rates $\left(r_{*}^{\mathrm{d}}, r_{*}^{\mathrm{c}}\right)$ such that the following conditions hold:

$$
\begin{aligned}
\mathbf{E}\left[\max \left\{G\left(d, \cdot, r_{*}^{\mathrm{d}}, r_{*}^{\mathrm{c}}\right), 0\right\}\right] & =d\left(1+r_{*}^{\mathrm{d}}\right) \\
\Pi\left(i_{\mathrm{G}}\left(d, r_{*}^{\mathrm{d}}\right), r_{*}^{\mathrm{c}}\right) & =e\left(1+r_{*}^{\mathrm{d}}\right) \\
S\left(r_{*}^{\mathrm{d}}\right)+e i_{\mathrm{G}}\left(d, r_{*}^{\mathrm{d}}\right)+d & =\left[\eta-i_{\mathrm{G}}\left(d, r_{*}^{\mathrm{d}}\right)\right] I .
\end{aligned}
$$

Condition (4) is the no-exit and no-entry condition for banks. Of course, the condition has to be applied to an individual bank. As the condition for an individual bank is obtained by dividing both sides in equation (4) by the number of banks, it is convenient to work directly with the aggregate condition. Condition (5) states that all entrepreneurs $i \geq i_{\mathrm{G}}\left(d, r_{*}^{\mathrm{d}}\right)$ invest, whereas all entrepreneurs $i<i_{\mathrm{G}}\left(d, r_{*}^{\mathrm{d}}\right)$ save. The spread $r_{*}^{\mathrm{c}}-r_{*}^{\mathrm{d}}$ is the premium that banks obtain for bearing macroeconomic risks. Condition (6) states that aggregate demand for loans is balanced by loan supply. It determines the critical investing entrepreneur $i_{\mathrm{G}}\left(d, r_{*}^{\mathrm{d}}\right)$, independent of equilibrium loan interest rates. If aggregate savings $S\left(r^{\mathrm{d}}\right)$ is increasing in $r^{\mathrm{d}}$, then $i_{\mathrm{G}}$ is decreasing in $d$ and $r^{\mathrm{d}}$.

Existence of temporary equilibria with financial intermediation is established as follows. Assume to this end that the productivity of the entrepreneur with quality level $\frac{\eta}{2}$ is on average greater than unity; that is,

$$
\frac{\left(1+\frac{\eta}{2}\right) \mathbf{E}[q] f(e+I)}{I}>1 .
$$

The following existence theorem is the foundation of our further analysis.

THEOREM 1. Consider a competitive banking system operating under limited liability. Let the following conditions be satisfied:

(i) The productivity of the entrepreneur with quality level $\frac{\eta}{2}$ is on average greater than unity and there exists an interest rate $\bar{r}^{\mathrm{d}}$ with

$$
0<\bar{r}^{\mathrm{d}}<\frac{\left(1+\frac{\eta}{2}\right) \mathbf{E}[q] f(e+I)}{I}-1,
$$

such that $\Pi(0,0)>e\left(1+\bar{r}^{\mathrm{d}}\right)>\Pi\left(\eta, \bar{r}^{\mathrm{d}}\right)$.

(ii) Aggregate saving $S\left(r^{\mathrm{d}}\right)$ is nondecreasing in $r^{\mathrm{d}}$ and

$$
S\left(r^{\mathrm{d}}\right)+\eta e>\left(1+r^{\mathrm{d}}\right) S^{\prime}\left(r^{\mathrm{d}}\right) \text { for all } 0 \leq r^{\mathrm{d}} \leq \bar{r}^{\mathrm{d}} .
$$

(iii) Let $r_{0}^{\mathrm{c}}>0$ denote the loan interest rate with $\Pi\left(0, r_{0}^{\mathrm{c}}\right)=e$, such that the entrepreneur with the lowest quality level $i=0$ will invest for $r^{\mathrm{d}}=0$. Assume that average repayments to banks are sufficiently high, so that

$$
\frac{\mathbf{E}\left[P\left(0, \cdot, r_{0}^{\mathrm{c}}\right)\right]}{\eta I} \geq 1
$$


Then for each $d \in(0, \bar{d}]$ there exists a unique TEFI, given by the interest rates $\left(r_{*}^{\mathrm{d}}(d), r_{*}^{\mathrm{c}}(d)\right) \in\left[0, r_{\mathrm{UB}}^{\mathrm{d}}\right] \times\left[r_{\mathrm{LB}}^{\mathrm{c}}, r_{\mathrm{UB}}^{\mathrm{c}}\right]$. The lower and upper bounds $r_{\mathrm{LB}}^{\mathrm{c}}>0, r_{\mathrm{UB}}^{\mathrm{d}}$, and $r_{\mathrm{UB}}^{\mathrm{c}}$ are defined by

$$
\Pi\left(0, r_{\mathrm{LB}}^{\mathrm{c}}\right)=e\left(1+r_{\mathrm{LB}}^{\mathrm{c}}\right), \quad \Pi\left(\eta, r_{\mathrm{UB}}^{\mathrm{d}}\right)=e\left(1+r_{\mathrm{UB}}^{\mathrm{d}}\right), \quad \Pi\left(\eta, r_{\mathrm{UB}}^{\mathrm{c}}\right)=e,
$$

respectively.

The proof of Theorem 1 is given by Gersbach and Wenzelburger (2004). Observe that Condition (ii) induces an upper bound for the savings elasticity of consumers, which is automatically satisfied for an inelastic savings function as well as for a savings function with elasticity less than unity. By setting an appropriate spread $r_{*}^{\mathrm{c}}-r_{*}^{\mathrm{d}}$, banks earn returns on capital that are high enough to ensure that there is no incentive to exit. It is intuitively clear that risk premia must be nonnegative. Formally, we show in Gersbach and Wenzelburger (2004):

COROLLARY 1. The equilibrium deposit rate $r_{*}^{\mathrm{d}}(d)$ is decreasing in $d \in$ $(0, \bar{d}]$. Risk premia are nonnegative, so that $r_{*}^{\mathrm{c}}(d)-r_{*}^{\mathrm{d}}(d) \geq 0$ for all $d \in(0, \bar{d}]$.

\section{EVOLUTION OF BANK CAPITAL}

In this section we describe the evolution of capital in the banking system. Adverse macroeconomic shocks may lead to bankruptcy of entrepreneurs and to low repayments to banks, thus affecting the evolution of bank capital. Let $d_{t} \in(0, \bar{d}]$ denote the capital base of the banking system at the beginning of a period $t$, where we allow the banking system to start with an arbitrary level $d_{0} \in(0, \bar{d}]$. At the beginning of period $t$, banks raise funds $S\left(r_{*}^{\mathrm{d}}\left(d_{t}\right)\right)+e i_{\mathrm{G}}\left(d_{t}, r_{*}^{\mathrm{d}}\left(d_{t}\right)\right)$, which must obey (2) and which have to be paid back with interest at the end of that period. Write $i_{*}\left(d_{t}\right):=i_{\mathrm{G}}\left(d_{t}, r_{*}^{\mathrm{d}}\left(d_{t}\right)\right)$ for the critical entrepreneur in a competitive equilibrium and let the equilibrium interest rates be $r_{*}^{\mathrm{c}}\left(d_{t}\right), r_{*}^{\mathrm{d}}\left(d_{t}\right)$ given by Theorem 1 . Then, given a shock $q_{t}$, the new level of bank capital $d_{t+1}$ is determined by

$$
d_{t+1}=\min \left\{G_{*}\left(d_{t}, q_{t}\right), \bar{d}\right\}, \quad d_{t} \in(0, \bar{d}],
$$

where, using the capital function of the banking system (3), the map $G_{*}\left(\cdot, q_{t}\right)$ : $(0, \bar{d}] \rightarrow \mathbf{R}$ is defined by

$$
G_{*}\left(d_{t}, q_{t}\right):=P\left(i_{*}(d), q, r_{*}^{\mathrm{c}}(d)\right)-\left[S\left(r_{*}^{\mathrm{d}}(d)\right)+e i_{*}(d)\right]\left(1+r_{*}^{\mathrm{d}}(d)\right) .
$$

Note that we account for the fact that excess capital above $\bar{d}$ will be distributed among old entrepreneurs only. Thus, possible dividend payments will affect neither savings nor investment decisions.

The map (7) is continuous in both arguments and describes a stochastic difference equation. Because $\left\{q_{t}\right\}_{t \in \mathbb{N}}$ is an iid process, the sequence of capital $\left\{d_{t}\right\}_{t \in \mathbb{N}}$ generated by (7) is a Markov process. If $d_{t+1} \geq 0$, then all depositors have been repaid and $d_{t+1}$ represents the banks' capital at the beginning of period $t+1$. If 
$d_{t+1}<0$, then the banks incur losses and $d_{t+1}$ is the amount of liabilities that could not be covered by loan repayments of entrepreneurs. In this case the banking system has negative equity and is bankrupt.

Finally, if $d \in(0, \bar{d}]$ is the level of bank capital of an arbitrary period, the aggregate income of the economy is

$$
Y(d, q)=e+\int_{i_{*}(d)}^{\eta}(1+i) q f(e+I) d i .
$$

The influence of bank capital $d$ on $Y(d, q)$ in our model is ambiguous, because the effect of $d$ on the critical entrepreneur $i_{*}(d)$ in a TEFI is ambiguous under the hypotheses of Theorem 1. On the one hand, higher bank capital allows the financing of more entrepreneurs. On the other hand, high bank capital induces low deposit rates and thus low savings. Which of the two effects dominates the other will essentially depend on consumer preferences. If the savings elasticity is sufficiently low, then aggregate income $Y$ is increasing in $d$.

\section{RISK PREMIA AND DEFAULT PROBABILITIES}

Having established the existence of temporary equilibria, we investigate the role of risk premia in the default probability of entrepreneurs. An entrepreneur with quality level $i$ enters bankruptcy if he is unable to fully pay back his credit, that is, if

$$
I\left(1+r^{\mathrm{c}}\right)>q(1+i) f(e+I) .
$$

The entrepreneur with the lowest quality level who is not bankrupt after encountering the shock $q$ is given by

$$
i_{\mathrm{B}}\left(i_{\mathrm{G}}, r^{\mathrm{c}}, q\right):= \begin{cases}i_{\mathrm{G}} & \text { if } q \geq q_{\mathrm{NB}}\left(i_{\mathrm{G}}, r^{\mathrm{c}}\right), \\ \frac{I\left(1+r^{\mathrm{c}}\right)}{q f(e+I)}-1 & \text { if } q_{\mathrm{TB}}\left(r^{\mathrm{c}}\right)<q<q_{\mathrm{NB}}\left(i_{\mathrm{G}}, r^{\mathrm{c}}\right), \\ \eta & \text { if } q \leq q_{\mathrm{TB}}\left(r^{\mathrm{c}}\right),\end{cases}
$$

where

$$
q_{\mathrm{NB}}\left(i_{\mathrm{G}}, r^{\mathrm{c}}\right):=\frac{I\left(1+r^{\mathrm{c}}\right)}{\left(1+i_{\mathrm{G}}\right) f(e+I)} \quad \text { and } \quad q_{\mathrm{TB}}\left(r^{\mathrm{c}}\right):=\frac{I\left(1+r^{\mathrm{c}}\right)}{(1+\eta) f(e+I)} .
$$

If shocks are sufficiently positive, $q \geq q_{\mathrm{NB}}\left(i_{\mathrm{G}}, r^{\mathrm{c}}\right)$, no entrepreneur enters bankruptcy and the bank profit is maximal. For shocks $q_{\mathrm{TB}}\left(r^{\mathrm{c}}\right)<q<q_{\mathrm{NB}}\left(i_{\mathrm{G}}, r^{\mathrm{c}}\right)$, all investing entrepreneurs with quality levels $i_{\mathrm{G}} \leq i<i_{\mathrm{B}}\left(i_{\mathrm{G}}, r^{\mathrm{c}}, q\right)$ enter bankruptcy, whereas entrepreneurs with quality levels $i \geq i_{\mathrm{B}}\left(i_{\mathrm{G}}, r^{\mathrm{c}}, q\right)$ pay back their loans fully.

In the case when entrepreneurs with sufficiently high quality never default, ${ }^{2}$ Gersbach and Wenzelburger (2004) show that the map $G_{*}$ that drives the evolution 
of bank capital takes the convenient form

$$
\begin{aligned}
& G_{*}(d, q)=I\left[\eta-i_{*}(d)\right]\left[r_{*}^{\mathrm{c}}(d)-r_{*}^{\mathrm{d}}(d)\right]+d\left(1+r_{*}^{\mathrm{d}}(d)\right) \\
& -\frac{1}{2} q f(e+I)\left[i_{\mathrm{B}}\left(i_{*}(d), r_{*}^{\mathrm{c}}(d), q\right)-i_{*}(d)\right]^{2} .
\end{aligned}
$$

Equation (9) reflects the fact that risk premia serve as a buffer against losses due to bankruptcies, which occur as soon as $i_{\mathrm{B}}\left(i_{*}(d), r_{*}^{\mathrm{c}}(d), q\right)>i_{*}(d)$. Notice that $q_{\mathrm{NB}}\left(i_{*}(d), r_{*}^{\mathrm{c}}(d)\right) \geq q_{\mathrm{NB}}\left(i_{\mathrm{G}}(0,0), r_{\mathrm{LB}}^{\mathrm{c}}\right)$, so that the probability for bankruptcies is positive independent of the capital base if $q_{\mathrm{NB}}\left(i_{\mathrm{G}}(0,0), r_{\mathrm{LB}}^{\mathrm{c}}\right)>\underline{q}$.

The default probability of entrepreneurs in a TEFI is now straightforward to formalize. For an arbitrary capital base $d \in(0, \bar{d}]$, if $q_{\mathrm{NB}}\left(i_{*}(d), r_{*}^{\mathrm{c}}(d)\right)>\underline{q}$, then the probability that entrepreneurs enter bankruptcy is positive and given by

$$
\operatorname{Prob}\left(i_{\mathrm{B}}\left(i_{*}(d), r_{*}^{\mathrm{c}}(d), \cdot\right)>i_{*}(d)\right)=\int_{\underline{q}}^{q_{\mathrm{NB}}\left(i_{*}(d), r_{*}^{\mathrm{c}}(d)\right)} \mu(d q)>0 .
$$

On the contrary, if $q_{\mathrm{NB}}\left(i_{*}(d), r_{*}^{\mathrm{c}}(d)\right) \leq \underline{q}$, then no entrepreneur enters bankruptcy with certainty. Proposition 1 in Gersbach and Wenzelburger (2004) demonstrates how a competitive banking system incorporates macroeconomic default risks of entrepreneurs. If the probability of bankruptcies amongst entrepreneurs is zero (i.e., $\left.q_{\mathrm{NB}}\left(i_{*}(d), r_{*}^{\mathrm{c}}(d)\right) \leq q\right)$, the risk premium for banks is zero, $r_{*}^{\mathrm{c}}(d)-r_{*}^{\mathrm{d}}(d)=$ 0 . As soon as the probability of bankruptcies among entrepreneurs is strictly positive (i.e., $q_{\mathrm{NB}}\left(i_{*}(d), r_{*}^{\mathrm{c}}(d)\right)>q$ ), the risk premium for banks is strictly positive, $r_{*}^{\mathrm{c}}(d)-r_{*}^{\mathrm{d}}(d)>0$. Note that the return on bank equity is given by the deposit rate $r_{*}^{\mathrm{d}}(d)$ and hence equilibrium intermediation margins only reflect the default risk of entrepreneurs.

It turns out that risk premia will become arbitrarily small if the capital base of the banking system tends toward zero. For this purpose, consider the case in which for sufficiently small $d \in(0, \bar{d}]$ the probability that high-quality entrepreneurs do not enter bankruptcy is positive. Using the definition in (8), we see that this is the case if

$$
q_{\mathrm{NB}}\left(i_{*}(d), r_{*}^{\mathrm{c}}(d)\right) \leq q_{\mathrm{NB}}\left(i_{\mathrm{G}}\left(0, r_{\mathrm{UB}}^{\mathrm{d}}\right), r_{\mathrm{UB}}^{\mathrm{c}}\right)<\bar{q} \text { for sufficiently small } d>0 \text {. }
$$

We are now in a position to state the following proposition.

THEOREM 2. Under the hypotheses of Theorem 1, let $q_{\mathrm{NB}}\left(i_{\mathrm{G}}\left(0, r_{\mathrm{UB}}^{\mathrm{d}}\right), r_{\mathrm{UB}}^{\mathrm{c}}\right)<$ $\bar{q}$. Then the risk premia will vanish with a vanishing capital base; that is,

$$
\lim _{d \rightarrow 0}\left[r_{*}^{\mathrm{c}}(d)-r_{*}^{\mathrm{d}}(d)\right]=0
$$

Theorem 2, whose proof is given in Gersbach and Wenzelburger (2004), has important implications. If a banking system has lost most of its capital, the risk premia decline, and hence the risk of a further decline of bank capital increases. At the limit where bank capital approaches zero, the risk premium vanishes. In order 
to explain this result, we observe that for a low level of bank capital a positive premium implies a very large return on equity ex post, if the macroeconomic shock turns out to be sufficiently favorable. In such circumstances, banks earn more from the vast majority of loans than the deposit rate. As equity is small in relation to deposits and loans, return on equity becomes very large. Because negative shocks imply zero equity, a small risk premium is sufficient to generate the ex ante return on equity demanded by shareholders.

\section{DEFAULT OF THE BANKING SYSTEM}

We will now investigate the possibility of a default of the banking system. We will show that the probability of a default of the banking system is positive if the capital base is below a certain threshold, which will be denoted by $d_{\text {crit }}$. This result is a consequence of the fact that risk premia may become arbitrarily small, as shown in Theorem 2. If a bank's capital base is too low, then banks will be unable to cover losses from bankruptcies of entrepreneurs. To formulate our next result, recall that bankruptcies of entrepreneurs occur with positive probability for all $d \in(0, \bar{d}]$, if $q_{\mathrm{NB}}\left(i_{\mathrm{G}}(0,0), r_{\mathrm{LB}}^{\mathrm{c}}\right)>\underline{q}$.

PROPOSITION 1. Under the hypotheses of Theorem 1, suppose that $q_{\mathrm{NB}}\left(i_{\mathrm{G}}(0,0), r_{\mathrm{LB}}^{\mathrm{c}}\right)>\underline{q}$. Then there exists a critical capital level $d_{\mathrm{crit}} \in(0, \bar{d}]$ such that the banking system defaults with positive probability; that is,

$$
\mathbf{P}\left(G_{*}(d, \cdot)<0\right)>0 \quad \text { whenever } d<d_{\text {crit }} .
$$

The proof of Proposition 1 is found in Gersbach and Wenzelburger (2004). The underlying economic forces that are at work here are reflected in (9). A level of bank capital below $d_{\text {crit }}$ makes the banking system vulnerable to default in two ways. First, the buffer against defaults of entrepreneurs is small. Second, the risk premium is small, and even medium-sized macroeconomic shocks may lead to a decline in bank capital.

The following argument now shows that a banking system may default in finite time with probability one, if the productivity of entrepreneurs is too low. Suppose there exists a critical shock $q_{\text {crit }}>\underline{q}$ such that the capital base will decrease for shocks below $q_{\text {crit }}$; that is,

$$
G_{*}(d, q)<d \text { for all } d \in(0, \bar{d}], q \leq q_{\text {crit }} .
$$

Then a series of sufficiently numerous shocks $q_{t}, \ldots, q_{t+\tau}$ below $q_{\text {crit }}$ will lead to a series of decreasing capital bases

$$
d_{t+1}=G_{*}\left(d_{t}, q_{t}\right)>\cdots>d_{t+1+\tau}=G_{*}\left(d_{t+\tau}, q_{t+\tau}\right)
$$

that will finally take on a value below zero, thus causing a default of the banking system. This argument is illustrated in Figure 1 for a series of five successive shocks. 


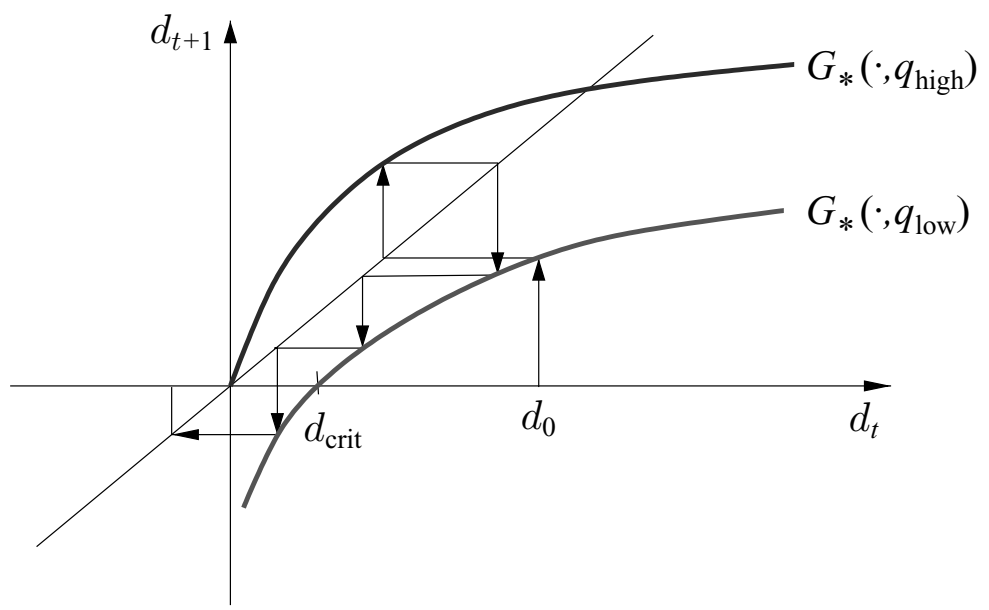

FIGURE 1. Bank default after a series of shocks $q_{\text {low }}, q_{\text {high }}, q_{\text {low }}, q_{\text {high }}, q_{\text {low }}$.

Let $T_{0}$ denote the first time for which the capital base of the banking system has vanished and the system has accumulated losses, that is, the first time for which $d_{T_{0}}<0$. The following theorem states that this event occurs in finite time with probability one, implying that the banking system will default in finite time with probability one.

THEOREM 3. Under the hypotheses of Theorem 1, let $q_{\mathrm{NB}}\left(i_{\mathrm{G}}(0,0), r_{\mathrm{LB}}^{\mathrm{c}}\right)>\underline{q}$ and suppose that

$$
\frac{P\left(i_{\mathrm{G}}(0,0), q, r_{\mathrm{UB}}^{\mathrm{c}}\right)}{I\left[\eta-i_{\mathrm{G}}(0,0)\right]}-1<\frac{S\left(r_{*}^{\mathrm{d}}(\bar{d})\right)}{I \eta} r_{*}^{\mathrm{d}}(\bar{d}) \quad \text { for all } q \leq q_{\mathrm{NB}}\left(i_{\mathrm{G}}(0,0), r_{\mathrm{LB}}^{\mathrm{c}}\right)
$$

Then for an arbitrary initial capital level $d_{0} \in(0, \bar{d}]$ the banking system will default in finite time with probability one; that is, $\mathbf{P}\left(T_{0}<\infty\right)=1$.

The proof of Theorem 3 is given in Gersbach and Wenzelburger (2004). It implies that a banking system cannot protect itself from a default. A default which will occur with certainty if the return on loans $P\left(i_{\mathrm{G}}(0,0), q, r_{\mathrm{UB}}^{\mathrm{c}}\right) /\left(I\left[\eta-i_{\mathrm{G}}(0,0)\right]\right)-1$ is too low. In this case a vicious circle starts. Repeated negative macroeconomic shocks lower the equity of banks until it ultimately lies below the critical level $d_{\text {crit }}$. Further negative macroeconomic shocks then lead to a downward spiral of bank capital. As equity declines, the risk premium decreases, which in turn increases the probability of further declines in bank capital. Over time the banking system will default. 


\section{CONCLUSION}

We investigated the default problem of a banking sector embedded in a dynamic macroeconomic model, where free entry and exit determine premia for aggregate risk. Our results suggest that vulnerabilities of a banking system may build up over time, while at the same time risk premia decline. This creates the danger of large-scale defaults of banks.

\section{NOTES}

1. The free-entry free-exit framework is a standard concept in industrial economics; see, for example, the recent work by Vives (2004), who integrates many free-entry models with innovation activities.

2. A sufficient condition is $q_{\mathrm{TB}}\left(r_{\mathrm{UB}}^{\mathrm{c}}\right)<\underline{q}$.

\section{REFERENCES}

Borio, Claude (2003) Towards a macroprudential framework for financial supervision and regulation. CESifo Economic Studies 49(2), 181-215.

Boyd, John H. and Edward C. Prescott (1986) Financial intermediary-coalitions. Journal of Economic Theory 38(2), 211-232.

Gersbach, Hans and Jan Wenzelburger (2004) Do Risk Premia Protect from Banking Crises? Discussion paper 519, Bielefeld University, Germany, and CEPR discussion paper 4935.

Gersbach, Hans and Jan Wenzelburger (2007) Stability of Banking Systems and Interest-Rate Interventions. Keele Economic Research paper No. 17.

Schreft, Stacey L. and Bruce D. Smith (1997) Money, banking, and capital formation. Journal of Economic Theory 73(1), 157-182.

Uhlig, Harald (1995) Transition and Financial Collapse. Discussion paper 66. CentER.

Vives, Xavier (2004) Innovation and Competitive Pressure. CEPR discussion paper 4369.

Williamson, Steve D. (1987) Financial intermediation, business failures, and real business cycles. Journal of Political Economy 95(6), 1196-1216. 